\title{
PENGARUH PEMBERIAN DOSIS KOMPOS DAN ARANG BAMBU TERHADAP PERTUMBUHAN Neolamarckia cadamba (Roxb.) Bosser PADA LAHAN MARJINAL
}

\section{(Effect of Dose Compost and Bamboo Biochar to The Growth of Neolamarckia cadamba (Roxb.) Bosser in Marginal Land)}

\author{
Faradila Mei Jayani ${ }^{a}$, Arief Juniarto ${ }^{a}$ \\ ${ }^{a}$ Staf Pengajar Program Studi Rekayasa Kehutanan Institut Teknologi Sumatera \\ Jalan Terusan Ryacudu, Way Hui, Jati Agung, Lampung Selatan 35365, Indonesia \\ E-mail:faradila.jayani@rh.itera.ac.id,arief.juniarto@rh.itera.ac.id
}

Diterima: 14 Agustus 2020, Direvisi: 10 September 2020, Disetujui: 07 November 2020

DOI: $10.31849 /$ forestra.v15i2.4718

\begin{abstract}
Marginal land is a land that has several limiting factors for a particular purpose so that it takes an effort to increase its productivity. Marginal land intended for planting activities has several limiting factors such as low soil organic matter and low pH. Efforts to increase the productivity of the marginal land can be done with the addition of fertilizer and soil ameliorant. This research aims to analyze combinations of compost and bamboo biochar, having the ability to the optimal increase growth of Neolamarckia cadamba (Roxb.) Bosser in marjinal land. The experimental design used Completely Randomized Factorial Design with two factors (compost and bamboo biochar). The addition of compost and bamboo biochar significantly increased the height, the diameter, and number of leaves of $N$. cadamba at 5\% level. DMRT result shows that the addition of $3 \mathrm{~kg}$ compost and $100 \mathrm{~g}$ bamboo biochar (K1A1) was the best treatment to increase the height, the diameter, and number of leaves.
\end{abstract}

Keywords: Bamboo biochar, Compost, Marginal land, Neolamarckia cadamba (Roxb.) Bosser

\begin{abstract}
ABSTRAK
Lahan marjinal merupakan lahan yang memiliki beberapa faktor pembatas untuk tujuan tertentu sehingga diperlukan suatu usaha untuk meningkatkan produktivitasnya. Lahan marjinal yang diperuntukkan untuk kegiatan penanaman memiliki beberapa faktor pembatas seperti bahan organik tanah yang rendah dan $\mathrm{pH}$ tanah yang masam. Upaya untuk meningkatkan produktivitas lahan marjinal tersebut dapat dilakukan dengan penambahan pupuk dan amelioran tanah. Penelitian ini bertujuan menganalisis kombinasi perlakuan kompos dan arang bambu untuk meningkatkan pertumbuhan Neolamarckia cadamba (Roxb.) Bosser pada lahan marjinal. Penelitian ini menggunakan Rancangan Acak Lengkap Faktorial dengan dua faktor yaitu pemberian kompos dan arang bambu. Kombinasi perlakuan kompos dan arang bambu berpengaruh nyata terhadap pertumbuhan tinggi, diameter, dan jumlah daun $N$. Cadamba pada taraf 5\%. Hasil uji lanjut menggunakan DMRT (Duncan's Multiple Range Test) menunjukkan bahwa pemberian kompos dengan dosis $3 \mathrm{~kg}$ dan arang bambu dengan dosis $100 \mathrm{~g}$ (K1A1)
\end{abstract}


menghasilkan pertumbuhan tinggi, diameter, dan $N$. cadamba paling bagus dibandingkan semua perlakuan yang diberikan.

Kata kunci: Arang bambu, Kompos, Lahan marjinal, Neolamarckia cadamba (Roxb.) Bosser

\section{PENDAHULUAN}

Indonesia yang memiliki potensi luas lahan 1.060.000 ha secara umum termasuk lahan marjinal (Yuwono, 2009). Lahan-lahan tersebut memiliki kesuburan tanah yang rendah. Lahan marjinal memiliki prospek untuk kegiatan penanaman namun perlu upaya untuk mengolahnya.

Lahan marjinal yaitu lahan yang memiliki beberapa faktor pembatas untuk tujuan tertentu. Lahan-lahan tersebut memiliki tingkat kesuburan yang rendah sehingga diperlukan suatu usaha untuk meningkatkan produktivitasnya. Faktor pembatas pada lahan marjinal yang diperuntukkan untuk budidaya tanaman salah satunya yaitu bahan organik tanah (Yuwono, 2009).

Upaya perbaikan lahan yang memiliki bahan organik rendah dapat dilakukan dengan penambahan kompos. Kompos terbuat dari bahan organik yang sudah mengalami proses dekomposisi oleh mikroorganisme pengurai. Kompos dapat memperbaiki sifat-sifat tanah dan mengandung unsur hara yang dibutuhkan oleh tanaman (Setyorini et al., 2003). Dengan penambahan kompos maka dapat meningkatkan pertumbuhan tanaman pada lahan yang memiliki tingkat kesuburan yang rendah.

Faktor pembatas lain pada lahan marjinal yang diperuntukkan untuk budidaya tanaman salah satunya yaitu $\mathrm{pH}$ tanah (Yuwono, 2009). Tanah masam yang memiliki nilai $\mathrm{pH}$ 4.5-5.5 menyebabkan pertumbuhan tanaman menjadi rendah, adanya akumulasi $\mathrm{Al}$, dan menyebabkan cekaman kekeringan (Eviati \& Sulaeman, 2009) (Sumner \& Noble, 2003). Tanaman biasanya mengalami pertumbuhan yang kurang bagus pada tanah masam karena adanya akumulasi alumunium ketika $\mathrm{pH}$ tanah $<5$. Alumunium pada kondisi tersebut menjadi larut sehingga menyebabkan pemangkasan akar yang parah akibatnya mengurangi penyerapan air dan nutrisi dari dalam tanah. Hal ini mengganggu pertumbuhan tanaman karena tanaman mengambil air dan unsur hara dari dalam 
tanah untuk kebutuhan pertumbuhannya (Sumner \& Noble, 2003).

Salah satu upaya mengatasi ketersediaan unsur hara dan air di dalam tanah yaitu dengan penambahan biochar atau arang hayati. Biochar adalah produk yang dihasilkan dari pirolisis biomassa pada suhu $<700{ }^{\circ} \mathrm{C}$. Biochar bisa berasal dari pirolisis kayu, bambu, sekam padi, kulit buah kakao, dan sebagainya (Bakar \& Azis, 2011) (Yuwono, 2017).

Biochar dapat digunakan sebagai bahan pembenah tanah. Biochar berperan sebagai penyimpan karbon karena dapat menyerap $\mathrm{CO}_{2}$ dari udara. Biochar memiliki kemampuan untuk mengikat air dan unsur hara sehingga dapat mengurangi kehilangan pupuk dalam tanah (Bakar \& Azis, 2011). Biochar juga mampu meningkatkan porositas tanah dan ketersediaan air tanah untuk pertumbuhan tanaman. Penambahan kompos 10 ton/ha dan biochar 40 ton/ha mampu meningkatkan porositas dan ketersediaan air tanah (Safitri et al., 2018).

Permasalahan yang sering muncul dalam upaya peningkatan kemampuan lahan marjinal untuk mendukung pertumbuhan tanaman yaitu mengenai dosis pupuk dan bahan pembenah tanah yang tepat. Penelitian ini bertujuan menganalisis pengaruh dosis kompos dan arang bambu terhadap pertumbuhan Neolamarckia cadamba (Roxb.) Bosser serta menganalisis kombinasi perlakuan kompos dan arang bambu yang paling optimal untuk meningkatkan pertumbuhan Neolamarckia cadamba (Roxb.) Bosser di lahan marjinal.

\section{METODE PENELITIAN}

1. Waktu dan Tempat Penelitian

Penelitian dilaksanakan bulan AprilOktober 2019 di lahan Kebun Raya Institut Teknologi Sumatera (ITERA). Pengujian karakteristik kimia tanah dan kompos dilakukan di Laboratorium PT Sucofindo, Bandar Lampung.

\section{Bahan dan Alat}

Bahan yang digunakan dalam penelitian yaitu kompos, arang bambu, dan bibit $N$. cadamba. Alat yang digunakan dalam penelitian yaitu neraca, cangkul, kaliper, penggaris, parang, alat pemotong rumput, tangki semprot, dan kamera. 


\section{Prosedur Penelitian}

a. Pengujian karakteristik kimia tanah dan kompos

Sampel tanah diambil pada lahan yang digunakan untuk penelitian untuk mengetahui karakteristik kimia tanah. Pengujian sifat kimia tanah dan kompos dilakukan di Laboratorium PT Sucofindo, Bandar Lampung. Karakteristik kimia tanah dan kompos yang diamati yaitu $\mathrm{pH}$, kandungan unsur C-organik, N, P, dan $\mathrm{K}$.

b. Penyiapan bibit $N$. cadamba

Bibit yang digunakan yaitu bibit $N$. cadamba berusia 3 bulan. Bibit yang dipilih yaitu bibit yang sehat dan seragam.

c. Penyiapan kompos dan arang bambu

Kompos yang digunakan terdiri atas tiga taraf yaitu:

K0: Kompos $0 \mathrm{~kg}$

$\mathrm{K} 1$ : Kompos $3 \mathrm{~kg}$

$\mathrm{K} 2$ : Kompos $5 \mathrm{~kg}$

Arang bambu yang digunakan terdiri atas dua taraf yaitu:
A0: Kompos $0 \mathrm{~g}$

A1: Kompos $100 \mathrm{~g}$

d. Pembersihan lahan dan pembuatan lubang tanam

Lahan terlebih dahulu dibersihkan dari gulma. Jarak lubang tanam yang digunakan yaitu $4 \mathrm{~m} \mathrm{x} 4$ $\mathrm{m}$. Ukuran lubang tanam yaitu $40 \mathrm{~cm}$ x $40 \mathrm{~cm} \mathrm{x} 40 \mathrm{~cm}$.

f. Pemberian perlakuan dan penanaman

Pemberian perlakuan kompos dan arang bambu dilakukan dengan meletakkannya pada lubang tanam. Bibit $N$. cadamba ditanam pada lubang tanam yang telah diberi perlakuan sesuai rancangan percobaan.

g. Pemeliharaan tanaman

Pemeliharaan tanaman dilakukan dengan penyiraman dan pembabatan gulma. Penyiraman tanaman dilakukan setiap sore hari. Pembabatan gulma dilakukan menggunakan mesin potong rumput dan sabit setiap sebulan sekali. 
4. Pengamatan dan pengambilan data

Parameter yang diamati pada penelitian ini yaitu pertumbuhan bibit $N$. cadamba yang terdiri atas pertumbuhan tinggi, diameter, dan jumlah daun. Pengamatan dilakukan setiap dua minggu sekali.

\section{Rancangan Penelitian}

Penelitian ini diracang menggunakan Rancangan Acak Lengkap Faktorial dua faktor. Faktor yang digunakan ada dua yaitu kompos dan arang bambu. Kombinasi kedua faktor tersebut menghasilkan enam perlakuan sebagai berikut:

$\mathrm{K} 0 \mathrm{~A} 0=0 \mathrm{~kg}$ kompos, $0 \mathrm{~g}$ arang bambu

$\mathrm{K} 0 \mathrm{~A} 1=0 \mathrm{~kg}$ kompos, $100 \mathrm{~g}$ arang bambu

$\mathrm{K} 1 \mathrm{~A} 0=3 \mathrm{~kg}$ kompos, $0 \mathrm{~g}$ arang bambu

$\mathrm{K} 1 \mathrm{~A} 1=3 \mathrm{~kg}$ kompos, $100 \mathrm{~g}$ arang bambu

$\mathrm{K} 2 \mathrm{~A} 0=5 \mathrm{~kg}$ kompos, $0 \mathrm{~g}$ arang bambu

$\mathrm{K} 2 \mathrm{~A} 1=5 \mathrm{~kg}$ kompos, $100 \mathrm{~g}$ arang bambu

Setiap perlakuan terdiri atas dua unit. Pengulangan dilakukan sebanyak lima kali sehingga menghasilkan 60 unit pengamatan. parameter pengamatan. Pengolahan data statistik menggunakan bantuan software SAS 9.1.3. Analisis data dilakukan menggunakan sidik ragam pada tingkat kepercayaan $95 \%$. Jika F hitung < F tabel, maka perlakuan yang diberikan tidak memberikan pengaruh nyata terhadap parameter pengamatan. Jika F hitung > F tabel, maka perlakuan memberikan pengaruh nyata terhadap parameter pengamatan. Jika perlakuan memberikan hasil yang berpengaruh nyata maka dilakukan uji lanjut menggunakan DMRT (Duncan's Multiple Range Test).

\section{HASIL DAN PEMBAHASAN}

1. Karakteristik Kimia Tanah pada Lokasi Penelitian

Pengujian karakteristik kimia digunakan untuk mengetahui tingkat kesuburan tanah pada lahan marjinal yang digunakan untuk lokasi penelitian. Hasil analisis karakteristik kimia ditunjukkan pada Tabel 1.

\section{Analisis Data}

Analisis data dilakukan untuk mengetahui pengaruh perlakuan terhadap 
Tabel 1. Hasil analisis sifat kimia tanah

\begin{tabular}{cccc}
\hline No. & $\begin{array}{c}\text { Sifat } \\
\text { Kimia }\end{array}$ & $\begin{array}{c}\text { Hasil Analisis } \\
(\%)\end{array}$ & Kriteria* \\
\hline 1 & $\mathrm{~N}$ & 2,40 & $\begin{array}{c}\text { Sangat } \\
\text { tinggi }\end{array}$ \\
& & & Rendah \\
2 & $\mathrm{P}_{2} \mathrm{O}_{5}$ & 0,05 & Rendah \\
3 & $\mathrm{~K}_{2} \mathrm{O}$ & 0,01 & Rendah \\
4 & C-organik & 0,69 & Masam \\
5 & pH & 4,55 & \\
\hline
\end{tabular}

*: (Eviati \& Sulaeman, 2009)

Tanah pada lokasi penelitian memiliki nilai $\mathrm{pH}$ dengan kategori masam dan memiliki kandungan unsur hara yang rendah. Kandungan unsur hara seperti $\mathrm{P}$ dan $\mathrm{K}$ tergolong rendah. Kandungan bahan organik tanah pada lokasi penelitian juga tergolong rendah. Hal ini menyebabkan tanaman kurang mampu untuk tumbuh dengan baik.

Tanah masam menyebabkan pertumbuhan tanaman menjadi rendah, adanya akumulasi $\mathrm{Al}$, dan menyebabkan cekaman kekeringan (Sumner \& Noble, 2003). Akumuasi Al akan menyebabkan toksik bagi tanaman karena mengikat unsur hara yang digunakan untuk pertumbuhan tanaman.
Hasil sidik ragam menunjukkan bahwa perlakuan kompos dan arang bambu memberikan pengaruh nyata terhadap pertumbuhan tinggi, diameter, dan jumlah daun N. cadamba. Hasil ini menandakan bahwa pemberian kompos dan arang bambu mampu meningkatkan pertumbuhan $N$. cadamba.

2. Pertumbuhan Tinggi dan Diameter $N$. cadamba

Hasil sidik ragam menunjukkan perlakuan kompos dan arang bambu berpengaruh nyata terhadap pertambahan tinggi dan diameter $N$. cadamba. Diagram pertumbuhan tinggi dan diameter $N$. cadamba yang diberi perlakuan kompos dan arang bambu ditunjukkan oleh gambar 1 dan 2.

\section{Pertumbuhan Tinggi $N$.} cadamba

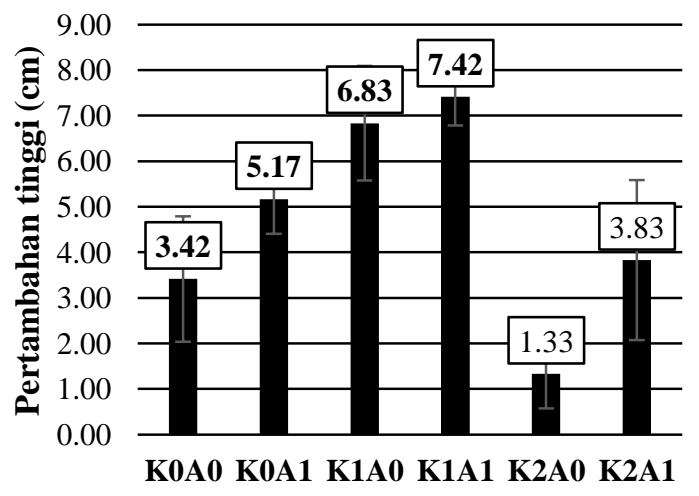


K0A0 = 0 kg kompos, $0 \mathrm{~g}$ arang bambu K0A1 = 0 kg kompos, $100 \mathrm{~g}$ arang bambu

$\mathrm{K} 1 \mathrm{A0}=3 \mathrm{~kg}$ kompos, $0 \mathrm{~g}$ arang bambu

$\mathrm{K} 1 \mathrm{~A} 1=3 \mathrm{~kg}$ kompos, $100 \mathrm{~g}$ arang bambu

$\mathrm{K2A0}=5 \mathrm{~kg}$ kompos, $0 \mathrm{~g}$ arang bambu

$\mathrm{K} 2 \mathrm{A1}$ = $5 \mathrm{~kg}$ kompos, $100 \mathrm{~g}$ arang bambu

Gambar 1. Diagram pertumbuhan tinggi $N$. cadamba yang diberi perlakuan kompos dan arang bambu

\section{Diagram Pertumbuhan}

\section{Diameter $N$. cadamba}

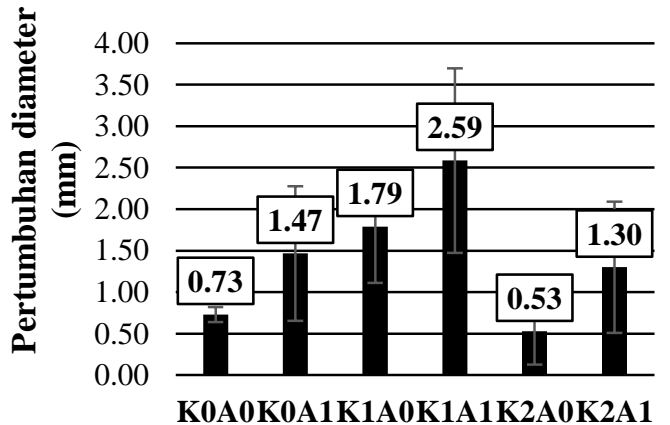

K0A0 = 0 kg kompos, 0 g arang bambu K0A1 = 0 kg kompos, $100 \mathrm{~g}$ arang bambu K1A0 = $3 \mathrm{~kg}$ kompos, $0 \mathrm{~g}$ arang bambu

K1A1 = $3 \mathrm{~kg}$ kompos, $100 \mathrm{~g}$ arang bambu $\mathrm{K2A0}=5 \mathrm{~kg}$ kompos, $0 \mathrm{~g}$ arang bambu

$\mathrm{K} 2 \mathrm{~A} 1$ = $5 \mathrm{~kg}$ kompos, $100 \mathrm{~g}$ arang bambu

Gambar 2. Diagram pertumbuhan diameter $N$. cadamba yang diberi perlakuan kompos dan arang bambu

Pemberian kompos mampu meningkatkan pertumbuhan tinggi dan diameter $N$. cadamba. Sesuai dengan yang ditunjukkan oleh Gambar 1 dan Gambar 2, pemberian kompos dengan dosis $3 \mathrm{~kg}$ (K1A0) mampu menghasilkan pertumbuhan tinggi dan diameter $N$. cadamba yang lebih baik dibandingkan dengan tanaman yang tidak diberi perlakuan (K0A0). Peningkatan pertumbuhan ini disebabkan kompos yang digunakan dalam penelitian ini mengandung unsur $\mathrm{N}$ dan $\mathrm{P}$ yang sangat tinggi seperti yang ditunjukkan Tabel 2. Unsur $\mathrm{N}$ merupakan bagian utama klorofil yang mempunyai fungsi utama dalam fotosintesis (Uchida, 2000). Unsur N mampu meningkatkan kualitas dan kuantitas tanaman. Unsur $\mathrm{P}$ berperan dalam menyimpan dan mentransfer energi saat fotosintesis. Unsur P juga berperan daam perkembangan akar.

Kompos yang digunakan dalam penelitian juga mengandung C-organik yang sangat tinggi sesuai yang ditunjukkan Tabel 1. Kandungan bahan organik tanah yang tinggi mampu meningkatkan kesuburan tanah (Setyorini et al., 2003). Kompos juga dapat memperbaiki sifat fisik, kimia, dan biologi tanah. Kompos mengandung unsur hara esensial yang dibutuhkan untuk pertumbuhan tanaman. Kompos dapat memperbaiki struktur tanah sehingga mempermudah penyerapan air dari tanah. 
Tabel 2. Hasil analisis sifat kimia kompos

\begin{tabular}{|c|c|c|c|}
\hline No. & $\begin{array}{l}\text { Sifat } \\
\text { kimia }\end{array}$ & $\begin{array}{c}\text { Hasil } \\
\text { analisis }(\%)\end{array}$ & Kriteria* \\
\hline 1 & $\mathrm{~N}$ & 1.07 & $\begin{array}{l}\text { Sangat } \\
\text { tinggi }\end{array}$ \\
\hline 2 & $\mathrm{P}_{2} \mathrm{O}_{5}$ & 0.74 & $\begin{array}{l}\text { Sangat } \\
\text { tinggi }\end{array}$ \\
\hline 3 & C-organik & 11.78 & $\begin{array}{c}\text { Sangat } \\
\text { tinggi }\end{array}$ \\
\hline 4 & $\mathrm{pH}$ & 7.25 & Netral \\
\hline
\end{tabular}

Penambahan arang bambu mampu meningkatkan pertumbuhan tinggi dan diameter $N$. cadamba seperti yang arang bambu dengan dosis $100 \mathrm{~g}$ (K0A1) mampu menghasilkan pertumbuhan tinggi dan diameter N. cadamba yang lebih baik dibandingkan dengan tanaman yang tidak diberi perlakuan (K0A0). Arang berperan sebagai penyimpan karbon karena dapat menyerap $\mathrm{CO}_{2}$ dari udara (Bakar \& Azis, 2011). Arang memiliki kemampuan untuk mengikat air dan unsur hara sehingga dapat mengurangi kehilangan pupuk dalam tanah.

Hasil uji lanjut menggunakan Duncan's Multiple Range Test (DMRT) pada ditunjukkan oleh Gambar 1 dan 2. Pemberian

Tabel 3 dan Tabel 4 menunjukkan bahwa pemberian kompos dengan dosis $3 \mathrm{~kg}$ dan arang bambu dengan dosis $100 \mathrm{~g}$ (K1A1) menghasilkan pertumbuhan tinggi dan diameter N. cadamba paling bagus diantara semua perlakuan. Pertumbuhan tinggi meningkat sebesar $117.06 \%$ dibandingkan dengan perlakuan kontrol. Pertumbuhan diameter meningkat sebesar 252.93\% dibandingkan dengan perlakuan kontrol.

Tabel 3. Pengaruh kompos dan arang bambu terhadap pertumbuhan tinggi $N$. cadamba

\begin{tabular}{ccrc}
\hline No & Perlakuan & $\begin{array}{c}\text { Pertambahan } \\
\text { tinggi }(\mathrm{cm})\end{array}$ & $\begin{array}{c}\text { Persentase } \\
\text { peningkatan }(\%)\end{array}$ \\
\hline 1 & K1A1 & $7.417 \mathrm{a}$ & 117.06 \\
2 & K1A0 & $6.833 \mathrm{ab}$ & 99.97 \\
3 & K0A1 & $5.167 \mathrm{bc}$ & 51.21 \\
4 & K2A1 & $3.833 \mathrm{c}$ & 12.17 \\
5 & K0A0 & $3.417 \mathrm{c}$ & 0.00 \\
& (kontrol) & & -60.99 \\
6 & K2A0 & $1.333 \mathrm{~d}$ & yang \\
*Perbedaan huruf & menunjukkan & perbedaan \\
\multicolumn{2}{l}{ signifikan pada $<0.05$}
\end{tabular}

Faradila Mei Jayani, Arief Juniarto/Wahana Forestra: Jurnal Kehutanan Vol 15 No 02/2020 
Tabel 4. Pengaruh kompos dan arang bambu terhadap pertumbuahan diameter $N$. cadamba

\begin{tabular}{rc}
\hline No Perlakuan & Pertumbuhan \\
diameter $(\mathrm{mm}) *$ & penambahan
\end{tabular}

$(\%)$

\begin{tabular}{llll}
\hline 1 & K1A1 & $2.587 \mathrm{a}$ & 252.93 \\
2 & K1A0 & $1.467 \mathrm{ab}$ & 178.37 \\
3 & K0A1 & $1.790 \mathrm{ab}$ & 144.20 \\
4 & K2A1 & $1.300 \mathrm{ab}$ & 77.35 \\
5 & K0A0 & $0.733 \mathrm{~b}$ & 0.00 \\
& (kontrol) & & \\
6 & K2A0 & $0.527 \mathrm{~b}$ & -28.10
\end{tabular}

*Perbedaan huruf menunjukkan perbedaan yang signifikan pada $\mathrm{p}<0.05$

Kompos dengan dosis $3 \mathrm{~kg}$ yang diberikan pada perlakuan K1A1 mengandung $\mathrm{C}$-organik, unsur $\mathrm{N}$, dan $\mathrm{P}$ yang sangat tinggi seperti yang ditunjukkan Tabel 2. Kandungan unsur hara yang tinggi tersebut yang menyebabkan peningkatan pertumbuhan pada N. cadamba. Arang bambu dengan dosis $100 \mathrm{~g}$ yang diberikan pada perlakuan K1A1 mampu meningkatkan pertumbuhan $N$. cadamba. Hal ini dikarenakan arang memiliki kemampuan untuk mengikat air dan unsur hara dari dalam tanah sehingga meningkatkan ketersediaanya untuk pertumbuhan tanaman (Bakar \& Azis, 2011).

Kompos yang digunakan dalam penelitian mengandung C-organik yang sangat tinggi seperti yang ditunjukkan oleh Tabel 2. C-organik merupakan penyusun utama bahan organik tanah. Pemberian kompos mampu meningkatkan bahan organik tanah sehingga meningkatkan kesuburan tanah (Setyorini et al., 2003). Bahan organik tanah mengandung unsur hara penting untuk pertumbuhan tanaman (Bot \& Benites, 2005). Bahan organik tanah juga menyerap dan menyimpan nutrisi menjadi bentuk yang tersedia bagi pertumbuhan tanaman.

Adanya kandungan C-organik, N, dan $\mathrm{P}$ yang tinggi dari kompos serta kemampuan arang untuk mengikat air dan unsur hara dari dalam tanah inilah yang mamapu meningkatkan pertumbuhan tinggi dan diameter $N$. cadamba. Pemberian kompos dan arang hayati mampu meningkatkan pertumbuhan tinggi $N$. cadamba (Ratnasari, 2013). 
3. Pertambahan Jumlah Daun N. cadamba

Hasil sidik ragam menunjukkan perlakuan kompos dan arang bambu berpengaruh nyata terhadap pertambahan jumlah daun $N$. cadamba. Diagram pertambahan jumlah daun $N$. cadamba yang diberi perlakuan kompos dan arang bambu ditunjukkan oleh Gambar 3.

\section{Diagram Pertambahan Jumlah Daun N. cadamba}

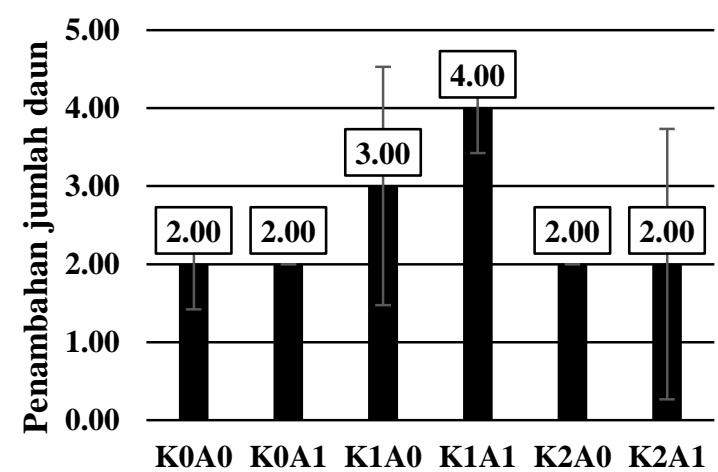

K0A0 = 0 kg kompos, 0 g arang bambu K0A1 = $0 \mathrm{~kg}$ kompos, $100 \mathrm{~g}$ arang bambu $\mathrm{K1A0}=3 \mathrm{~kg}$ kompos, $0 \mathrm{~g}$ arang bambu K1A1 = $3 \mathrm{~kg}$ kompos, $100 \mathrm{~g}$ arang bambu $\mathrm{K} 2 \mathrm{A0}=5 \mathrm{~kg}$ kompos, $0 \mathrm{~g}$ arang bambu $\mathrm{K} 2 \mathrm{~A} 1$ = $5 \mathrm{~kg}$ kompos, $100 \mathrm{~g}$ arang bambu

Gambar 3. Diagram pertambahan jumlah daun $N$. cadamba yang diberi perlakuan kompos dan arang bambu

Pemberian kompos mampu meningkatkan jumlah daun $N$. cadamba. Sesuai dengan yang ditunjukkan oleh Gambar 3, pemberian kompos dengan dosis $3 \mathrm{~kg}$ (K1A0) mampu menghasilkan pertambahan jumlah daun $N$. cadamba yang lebih banyak dibandingkan dengan tanaman yang tidak diberi perlakuan (K0A0). Peningkatan pertumbuhan ini disebabkan kompos yang digunakan dalam penelitian ini mengandung unsur $\mathrm{N}$ yang sangat tinggi seperti yang ditunjukkan Tabel

2. Unsur $\mathrm{N}$ merupakan komponen utama yang menyusun klorofil pada daun sehingga fungsi unsur $\mathrm{N}$ yaitu meningkatkan kualitas dan kuantitas biomassa pada tanaman berdaun (Uchida, 2000).

Penambahan arang bambu mampu meningkatkan jumlah daun $N$. cadamba seperti yang ditunjukkan oleh Gambar 3. Pemberian arang bambu dengan dosis $100 \mathrm{~g}$ (K0A1) mampu menghasilkan pertambahan jumlah daun $N$. cadamba yang lebih banyak dibandingkan dengan tanaman yang tidak diberi perlakuan (K0A0). Peningkatan pertambahan jumlah daun ini dikarenakan arang memiliki kemampuan untuk mengikat air dan unsur hara yang dibutuhkan untuk pertumbuhan $N$. cadamba termasuk penambahan jumlah daun (Bakar \& Azis, 2011). Pemberian arang hayati berperan 
dalam pembenaha sifat kimia tanah termasuk ketersediaan unsur $\mathrm{N}$ dan $\mathrm{Mg}$. Kedua unsur ini merupakan komponen utama pembentukan klorofil pada daun (Sukartono \& Utomo, 2012).

Hasil uji lanjut menggunakan Duncan's Multiple Range Test (DMRT) pada Tabel 5 menunjukkan bahwa pemberian kompos dengan dosis $3 \mathrm{~kg}$ dan arang bambu dengan dosis $100 \mathrm{~g}$ (K1A1) menghasilkan pertambahan jumlah daun $N$. cadamba yang paling banyak dibandingkan dengan semua perlakuan. Pertambahan jumlah daun meningkat sebesar $100 \%$ dibandingkan dengan perlakuan kontrol.

Tabel 5. Pengaruh kompos dan arang bambu terhadap penambahan jumlah daun $N$. cadamba

\begin{tabular}{cccc}
\hline No Perlakuan & $\begin{array}{c}\text { Penambahan } \\
\text { jumlah daun* }\end{array}$ & $\begin{array}{c}\text { Persentase } \\
\text { penambahan } \\
(\%)\end{array}$ \\
\hline 1 & K1A1 & $4 \mathrm{a}$ & 100 \\
2 & K1A0 & $3 \mathrm{ab}$ & 50 \\
3 & K2A0 & $2 \mathrm{ab}$ & 0 \\
4 & K0A1 & $2 \mathrm{ab}$ & 0 \\
5 & K2A1 & $2 \mathrm{ab}$ & 0 \\
6 & K0A0 & $2 \mathrm{ab}$ & 0 \\
& (kontrol) & &
\end{tabular}

*Perbedaan huruf menunjukkan perbedaan yang signifikan pada $\mathrm{p}<0.05$
Kompos dengan dosis $3 \mathrm{~kg}$ yang diberikan pada perlakuan K1A1 mengandung unsur $\mathrm{N}$ yang sangat tinggi seperti yang ditunjukkan Tabel 2. Kandungan unsur $\mathrm{N}$ yang tinggi ini menyebabkan penambahan jumlah daun karena unsur $\mathrm{N}$ merupakan komponen utama penyusun klorofil pada daun (Uchida, 2000). Arang bambu dengan dosis $100 \mathrm{~g}$ yang diberikan pada perlakuan K1A1 memiliki kemampuan untuk mengikat air dan unsur hara dari dalam tanah. Penambahan arang bambu ini mampu mengikat air dan unsur hara dari dalam tanah termasuk unsur $\mathrm{N}$ dan Mg yang merupakan komponene utama penyusun klorofil pada daun.

\section{KESIMPULAN DAN SARAN}

\section{A. Kesimpulan}

Pemberian kompos dan arang bambu mampu meningkatkan pertumbuhan $N$. cadamba pada tanah marjinal yang mempunya bahan organik tanah yang rendah dan $\mathrm{pH}$ tanah yang masam. Kombinasi perlakuan kompos dan arang bambu berpengaruh nyata terhadap pertumbuhan tinggi, diameter, dan jumlah daun $N$. 
Cadamba pada taraf 5\%. Hasil uji lanjut menggunakan DMRT menunjukkan bahwa pemberian kompos dengan dosis $3 \mathrm{~kg} / \mathrm{bibit}$ dan arang bambu dengan dosis $100 \mathrm{~g} / \mathrm{bibit}$ (K1A1) menghasilkan pertumbuhan tinggi, diameter, dan $N$. cadamba paling bagus dibandingkan semua perlakuan yang diberikan.

\section{B. Saran}

Pengelola Kebun Raya ITERA perlu mengaplikasikan dosis kompos dan arang bambu terbaik yang dihasilkan pada penelitian ini kompos dengan dosis $3 \mathrm{~kg}$ dan arang bambu dengan dosis $100 \mathrm{~g}$ untuk luasan lahan yang lebih besar. Perlu dilakukannya pengujian dosis ini terhadap jenis tanaman lain di Kebun Raya ITERA.

\section{UCAPAN TERIMA KASIH}

\section{(ACKNOWLEDGEMENT)}

Ucapan terima kasih penulis berikan kepada Institut Teknologi Sumatera (ITERA) yang telah memberikan dana hibah untuk penelitian ini melalui program hibah penelitian mandiri dengan nomor kontrak penelitian B/348/IT9.C1/PT.01.03/2019.

\section{DAFTAR PUSTAKA}

Bakar, B. A., \& Azis, A. (2011). Arang Hayati (BIOCHAR) sebagai Bahan Pembenah Tanah. Balai Pengkajian Teknologi Pertanian (BPTP) Aceh, 1-2.

Bot, A., \& Benites, J. (2005). The importance of soil organic matter: Key to droughtresistant soil and sustained food and production. Food And Agriculture Organization of The United Nations.

Eviati, \& Sulaeman. (2009). Analisis Kimia Tanah, Tanaman, Air, dan Pupuk. Balai Penelitian Tanah.

Ratnasari, D. (2013). Respon pertumbuhan semai jabon (Anthocephalus cadamba Roxb. Miq.) terhadap pemberian kompos dan arang tempurung kelapa pada media limbah tambang pasir. Institut Pertanian Bogor.

Safitri, I. N., Setiawati, T., \& Bowo, C. (2018). Biochar dan kompos untuk peningkatan sifat fisika tanah dan efisiensi penggunaan air. Techno: Jurnal Penelitian, 7(1), 116-127.

Setyorini, D., Saraswati, R., \& Anwar, E. K. (2003). Kompos. In R. D. M. Simanungkalit, D. A. Suriadikarta, R. Saraswati, D. Setyorini, \& W. Hartatik (Eds.), Pupuk Organik dan Pupuk Hayati. Balai Besar Penelitian dan Pengembangan Sumber Daya Lahan Pertanian.

Sukartono, \& Utomo, W. (2012). Peranan Biochar sebagai Pembenah Tanah pada 
Pertanaman Jagung di Tanah Lempung Berpasir (Sandy Loam) Semiarid Tropis Lombok Utara. Buana Sains, 12(1), 9198.

Sumner, M. E., \& Noble, A. D. (2003). Soil Acidification: The World Story. In Z. Rengel (Ed.), Handbook of Soil Acidity. Marcel Dekker Inc.

Uchida, R. (2000). Essential Nutrients for Plant Growth: Nutrient Functions and Deficiency Symptoms. In J. A. Silva \& R. Uchida (Eds.), Plant Nutrient Management in Hawaii's Soils, Approaches for Tropical and Subtropical Agriculture. College of Tropical Agriculture and Human Resources, University of Hawaii at Manoa.

Yuwono, N. W. (2009). Membangun Kesuburan Tanah di Lahan Marjinal. Jurnal Ilmu Tanah Dan Lingkungan, 9(2), 137-141.

Yuwono, N. W. (2017). Teknologi tribio untuk mempercepat proses perbaikan kesuburan tanah di lahan kering. Prosiding Seminar Nasional Perbaikan Kualitas Lahan Kering 2017: Perbaikan Kualitas Lahan Kering Untuk Meningkatkan Produksi Pertanian Dan Ketahanan Pangan, 61-69. 